\title{
Mechanisms by Which Dehydration May Lead to Chronic Kidney Disease
}

\author{
C. Roncal-Jimenez ${ }^{\mathrm{a}} \quad$ M.A. Lanaspa ${ }^{\mathrm{a}} \quad$ T. Jensen ${ }^{\mathrm{a}} \quad$ L.G. Sanchez-Lozada ${ }^{\mathrm{b}}$ \\ R.J. Johnson ${ }^{a}$ \\ aDivision of Kidney Diseases and Hypertension, University of Colorado Denver, Aurora, Colo., USA; \\ bLaboratory of Renal Physiopathology and Nephrology Department, INC Ignacio Chavez, Mexico City, Mexico
}

\section{Key Words}

Dehydration - Chronic kidney disease - Vasopressin .

Fructose $\cdot$ Uric acid

\begin{abstract}
Dehydration, a condition that characterizes excessive loss of body water, is well known to be associated with acute renal dysfunction; however, it has largely been considered reversible and to be associated with no long-term effects on the kidney. Recently, an epidemic of chronic kidney disease has emerged in Central America in which the major risk factor seems to be recurrent heat-associated dehydration. This has led to studies investigating whether recurrent dehydration may lead to permanent kidney damage. Three major potential mechanisms have been identified, including the effects of vasopressin on the kidney, the activation of the aldose reductase-fructokinase pathway, and the effects of chronic hyperuricemia. The discovery of these pathways has also led to the recognition that mild dehydration may be a risk factor in progression of all types of chronic kidney diseases. Furthermore, there is some evidence that increasing hydration, particularly with water, may actually prevent CKD. Thus, a whole new area of investigation is developing that focuses on the role of water and osmolarity and their influence on kidney function and health.

(c) 2015 S. Karger AG, Basel
\end{abstract}

Dehydration classically refers to the excessive loss of body water through conditions such as diarrhea, sweating, or urinary losses, but among the lay public dehydration may also refer to the loss of both water and salt leading to a hypovolemic state [1]. Dehydration has multiple effects on the kidney, leading to urinary concentration due to activation of vasopressin that occurs as a result of increase in serum osmolarity due to the loss of body water. Classically dehydration results in a 'pre-renal state' associated with intrarenal vasoconstriction but with relative maintenance of glomerular filtration rate (GFR). If volume depletion is severe, GFR falls, but it has been thought to be completely reversible with hydration, unless ischemia results in acute kidney injury (AKI). Nevertheless, AKI is thought be largely reversible. Hence, dehydration has not been classically considered a risk factor for chronic kidney disease (CKD).

In recent years, the concept that dehydration does not cause CKD has been challenged. This has been highlighted in recent studies investigating a mysterious form of CKD that has been epidemic in Central America [2, 3]. The disease, which has been named Mesoamerican Nephropathy, is being observed at remarkable frequency among male agricultural workers on the Pacific Coast, particularly in Nicaragua and El Salvador. The condition is distinct from other major causes of CKD such as high

\begin{tabular}{ll}
\hline KARGER 125:30 & $\begin{array}{l}\text { (2) 2015 S. Karger AG, Basel } \\
0250-6807 / 15 / 0667-0010 \$ 39.50 / 0 \quad \text { Karger }\end{array}$ \\
$\begin{array}{l}\text { E-Mail karger@karger.com } \\
\text { www.karger.com/anm }\end{array}$ & $\begin{array}{l}\text { This is an Open Access article licensed under the terms of the } \\
\text { Creative Commons Attribution-NonCommercial 3.0 Un- } \\
\text { ported license (CC BY-NC) (www.karger.com/OA-license), } \\
\text { applicable to the online version of the article only. Distribu- } \\
\text { tion permitted for non-commercial purposes only. }\end{array}$
\end{tabular}

Richard J. Johnson

Division of Renal Diseases and Hypertension

University of Colorado Denver

Aurora, CO 80045 (USA)

E-Mail Richard.johnson@ucdenver.edu 


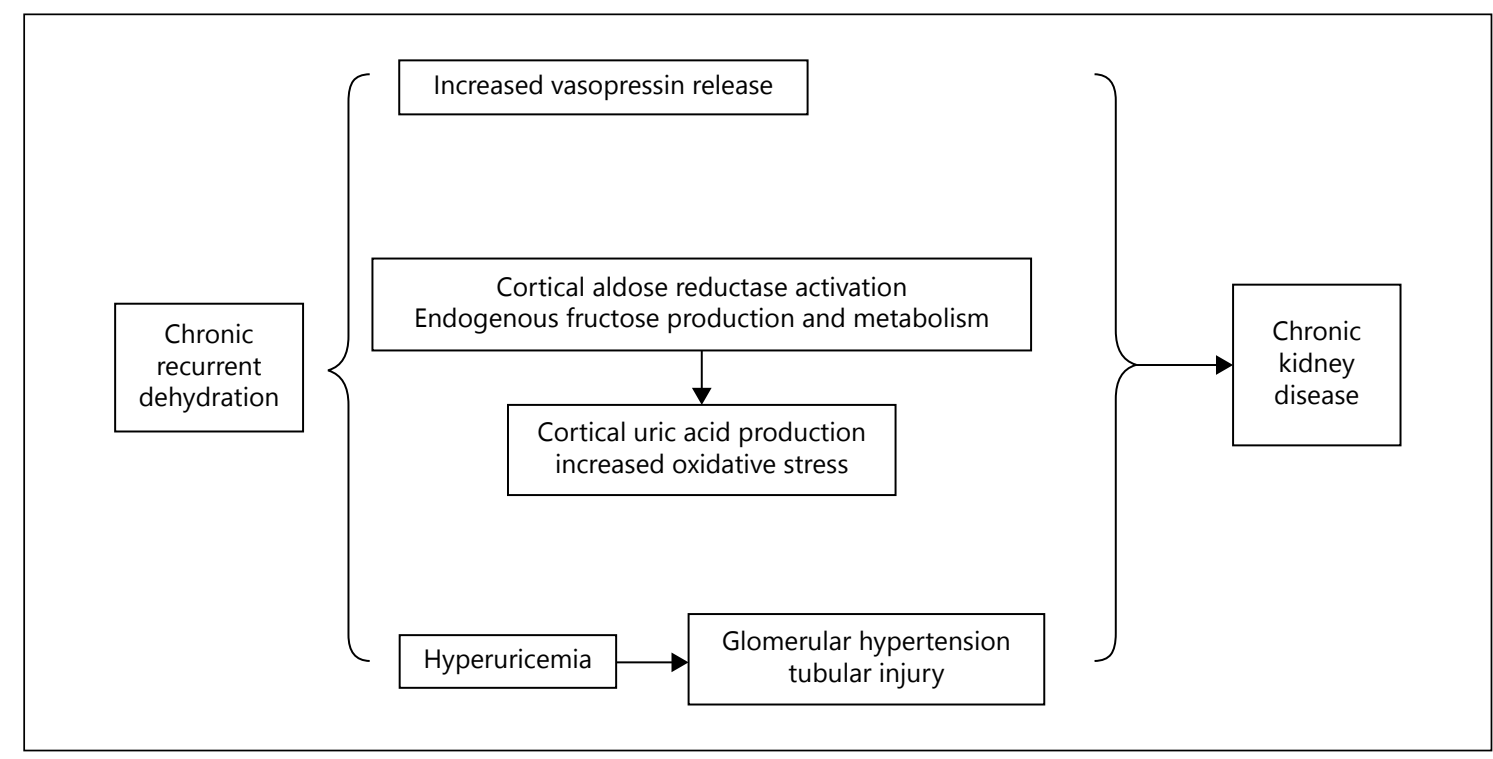

Fig. 1. Proposed model for chronic dehydration induced CKD.

blood pressure and diabetes. Most subjects are used to working many hours in sugarcane fields under very hot conditions, and dehydration is common in this group [4, 5]. Renal biopsies, when performed, show chronic tubulointerstitial disease, often with evidence for glomerular ischemia [6]. While the etiology of the disease remains unknown, a favorite hypothesis is that it may relate to recurrent volume depletion and dehydration $[2,3]$. It has also been suggested that dehydration and volume depletion play a major role in increasing the risk of kidney injury from pesticides, agrochemicals, heavy metals or other potential exposures that are still under investigation $[2,3]$.

Our group and others have pursued three major possible mechanisms by which dehydration and volume depletion may cause CKD (figure 1). First, there is increasing evidence that elevations in vasopressin may have a role in causing or exacerbating CKD [7]. Vasopressin is increased in the setting of volume depletion due to the effects of hyperosmolarity to stimulate vasopressin release from the posterior pituitary. Vasopressin is also elevated in laboratory animals with CKD. When increased amounts of water are administered, the vasopressin levels can be suppressed and the progression of renal damage can be slowed. Thus, vasopressin has emerged as a likely mediator of kidney damage [8].

Second, it is known that hyperosmolarity can activate a variety of pathways, including stimulation of va- sopressin, the central sympathetic nervous system, and the aldose reductase pathway. Recently, our group showed using laboratory rats that dehydration-associated hyperosmolarity can activate the aldose reductase pathway in the renal cortex, resulting in the generation of sorbitol that can then be converted to fructose [9]. The endogenous fructose that is generated can then be metabolized by fructokinase, an enzyme present in the proximal tubule [10]. The fructose is metabolized to fructose-1-phosphate, but in the process there is marked intracellular ATP consumption, leading to intracellular phosphate depletion, activation of AMP deaminase, and the generation of uric acid, oxidative stress, and the production of chemokines [10]. The local oxidative stress results in tubular injury and stimulates fibrosis [9]. Indeed, animals recurrently exposed to heat and water restriction developed chronic kidney disease, but this was not observed in mice genetically lacking fructokinase [9]. Thus, activation of the aldose reductase-fructokinase pathway is another mechanism by which recurrent dehydration may lead to CKD.

Third, heat-associated dehydration may result in hyperuricemia, both due to increased production (associated with low-grade, subclinical rhabdomyolysis from strenuous exertion) and reduced urate excretion associated with renal vasoconstriction [11]. Hyperuricemia is common in subjects with Mesoamerican Nephropathy. In turn, hyperuricemia has been 
recognized as a risk factor for both acute and chronic kidney injury $[12,13]$. The mechanism may involve uric acid-induced vasculopathy with the development of glomerular hypertension [14], as well as direct tubular effects resulting in epithelial mesenchymal transition [15].

Research on Mesoamerican nephropathy has led to renewed interest in the role of dehydration as a potential causative factor in CKD. More recently, patients suffering from conditions that appear similar to Mesoamerican nephropathy have been reported from other countries, including Brazil, Sri Lanka, and Australia $[16,17]$. Thus, it is possible that recurrent dehydration may be a general cause of $\mathrm{CKD}$, which is being recognized only in recent days.

Furthermore, provocative epidemiological studies suggest that increasing fluid intake can slow the progression of CKD. Indeed, some epidemiological studies suggest that a urinary output of 3 liters per day provides significant renal protection compared to subjects excreting 1 to 1.5 liters per day $[18,19]$. If true, this suggests that, while dehydration may be a risk factor for CKD, increasing water consumption to a level that is more than what is considered normal intake may provide superior protection. Indeed, a clinical trial is in process to test this fascinating possibility.

A caveat is that not all fluids should be considered equal. Soft drinks and sugary beverages, for example, might be expected to worsen kidney disease due to their high fructose content that can directly provide substrate to the fructokinase pathway. Indeed, experimen- tal studies show fructose can induce renal injury and accelerate CKD in laboratory animals [20,21]. Furthermore, some clinical studies also suggest that the intake of sugary beverages may increase the risk for kidney disease [22].

In conclusion, for decades the prevention and treatment of kidney disease has been directed primarily toward good blood pressure management and tight control of diabetes. New studies, initiated from research on Mesoamerican nephropathy, have identified dehydration as another likely risk factor. More recent studies are investigating whether protection can occur not only by preventing dehydration but also by encouraging increased intake of water. Clinical studies are now in progress, but these discoveries may help shepherd new approaches to prevent and slow the progression of kidney disease.

\section{Financial Support}

Supported by a grant from Danone Research.

\section{Disclosure Statement}

RJJ, CRJ and LGS have received research funding from Danone Research to explore mechanisms by which dehydration may cause CKD. RJJ, CRJ, LGL and MAL are also members of Colorado Research Partners LLC that is developing inhibitors of fructose metabolism. RJJ also has shares and is on the Scientific Board of XORT therapeutics.

\section{References}

1 Parikh C, Berl T: Disorders of Water Metabolism. In: Floege J, Johnson RJ, Feehally J, eds. Comprehensive Clinical Nephrology. 4th edition ed. Philadelphia, Elsevier, 2010.

-2 Correa-Rotter R, Wesseling C, Johnson $\mathrm{RJ}$ : CKD of Unknown Origin in Central America: The Case for a Mesoamerican Nephropathy. Am J Kidney Dis 2014;63:506520.

3 Laws RL, Brooks DR, Amador JJ, et al: Changes in kidney function among Nicaraguan sugarcane workers. Int J Occup Environ Health 2015;2049396714Y0000000102.

4 Crowe J, Wesseling C, Solano BR, et al: Heat exposure in sugarcane harvesters in Costa Rica. Am J Ind Med 2013;56:11571164.

5 Crowe J, Nilsson M, Kjellstrom T, Cerdas M, Johnson R, Wesseling C: Repeated pre and post-shift urinalyses show kidney dysfunction among Costa Rican sugarcane cutters exposed to heat stress. Occup Environ Med 2014;71(suppl 1):A51.

6 Wijkstrom J, Leiva R, Elinder CG, et al: Clini$\mathrm{cal}$ and pathological characterization of mesoamerican nephropathy: a new kidney disease in central america. Am J Kidney Dis 2013;62:908-918.

$\checkmark 7$ Bankir L, Bouby N, Ritz E; Vasopressin: a novel target for the prevention and retardation of kidney disease? Nat Rev Nephrol 2013; 9:223-239.

$>8$ Bouby N, Bachmann S, Bichet D, Bankir L: Effect of water intake on the progression of chronic renal failure in the 5/6 nephrectomized rat. Am J Physiol 1990;258(4 Pt 2): F973-F979.

-9 Roncal Jimenez CA, Ishimoto T, Lanaspa MA, et al: Fructokinase activity mediates de- hydration-induced renal injury. Kidney Int 2014;86:294-302.

10 Cirillo P, Gersch MS, Mu W, et al: Ketohexokinase-dependent metabolism of fructose induces proinflammatory mediators in proximal tubular cells. J Am Soc Nephrol 2009;20: 545-553.

11 Knochel JP, Dotin LN, Hamburger RJ: Heat stress, exercise, and muscle injury: effects on urate metabolism and renal function. Ann Intern Med 1974;81:321-328.

-12 Lapsia V, Johnson RJ, Dass B, et al: Elevated uric acid increases the risk for acute kidney injury. Am J Med 2012;125:302.e9e17.

13 Johnson RJ, Nakagawa T, Jalal D, SanchezLozada LG, Kang DH, Ritz E: Uric acid and chronic kidney disease: which is chasing which? Nephrol Dial Transplant 2013;28: 2221-2228. 
14 Sanchez-Lozada LG, Tapia E, Santamaria J, et al: Mild hyperuricemia induces vasoconstriction and maintains glomerular hypertension in normal and remnant kidney rats. Kidney Int 2005;67:237-247.

15 Ryu ES, Kim MJ, Shin HS, et al: Uric acidinduced phenotypic transition of renal tubular cells as a novel mechanism of chronic kidney disease. Am J Physiol Renal Physiol 2013; 304:F471-F480.

16 Jayatilake N, Mendis S, Maheepala P, Mehta FR: Chronic kidney disease of uncertain aetiology: prevalence and causative factors in a developing country. BMC Nephrol 2013;14:180.
7 Paula Santos U, Zanetta DM, Terra-Filho M, Burdmann EA. Burnt sugarcane harvesting is associated with acute renal dysfunction. Kidney Int 2015;89:792-799.

18 Clark WF, Sontrop JM, Macnab JJ, et al: Urine volume and change in estimated GFR in a community-based cohort study. C J Am Soc Nephrol 2011;6:2634-2641.

19 Strippoli GF, Craig JC, Rochtchina E, Flood VM, Wang JJ, Mitchell P: Fluid and nutrient intake and risk of chronic kidney disease. $\mathrm{Ne}$ phrology (Carlton) 2011;16:326-334.
20 Nakayama T, Kosugi T, Gersch M, et al: Dietary fructose causes tubulointerstitial injury in the normal rat kidney. Am J Physiol Renal Physiol 2010;298:F712-F720.

21 Gersch MS, Mu W, Cirillo P, et al: Fructose, but not dextrose, accelerates the progression of chronic kidney disease. Am J Physiol Renal Physiol 2007;293:F1256-F1261.

22 Shoham DA, Durazo-Arvizu R, Kramer H, et al: Sugary soda consumption and albuminuria: results from the National Health and Nutrition Examination Survey, 1999-2004. PLoS One 2008;3:e3431. 